\begin{tabular}{|c|c|c|}
\hline \multirow[b]{2}{*}{ EVCDI I ENT } & Int.J.Curr.Microbiol.App.Sci (2021) 10(08): 88-91 & \\
\hline & $\begin{array}{l}\text { International Journal of Current Microbiology and Applied Sciences } \\
\text { ISSN: 2319-7706 Volume } \mathbf{1 0} \text { Number } 08 \mathbf{( 2 0 2 1 )} \\
\text { Journal homepage: } \underline{\text { http://www.ijcmas.com }}\end{array}$ & 98 \\
\hline PUBLISHERS & & www.ijcmas.com \\
\hline
\end{tabular}

Case Study https://doi.org/10.20546/ijcmas.2021.1008.011

\title{
Handling of Dystocia due to Single Pup Syndrome in Labrador Bitch: A Case Report
}

\author{
Abhay Kumar Meena*, Pravin Kumar Meena, Manish Kumar and Krishan Yadav
}

Department of Veterinary Gynaecology and Obstetrics, Post Graduate Institute of Veterinary Education and Research (PGIVER), Rajasthan University of Veterinary and Animal Science (RAJUVAS), Bikaner, Rajasthan, India

*Corresponding author

\section{A B S T R A C T}

Keywords

Single puppy, bitch, whelping

Article Info

Accepted:

12 July 2021

Available Online:

10 August 2021
Successful handling of dystocia due to single puppy syndrome in a Labrador bitch in her first parity with history of mating 68 days ago and failure to deliver on excepted date of whelping. On examination per vaginal limbs was palpable without any movement. On radiographic examination, it was revealed presence of single fully grown fetus with posterior presentation in uterus. This case was handled successfully with repeated doses of oxytocin and calcium therapy with fluids.

\section{Introduction}

Dogs are polytocous animals with overall mean litter size of 5.4 (range 1 - 18) (Borge et al., 2011). But in some instances, single fetus pregnancy is observed in bitches termed as "single pup syndrome" (Jackson, 2004).

A single puppy can cause several problems at the time of whelping; hence this condition is considered as a high-risk pregnancy. In single pup syndrome, there may be inadequate cortisol release from the foetus to initiate PGF2arelease by the endometrium, which initiates $\mathrm{CL}$ regression and whelping ( $\mathrm{M}$. H.Pitroda, 2019). Due to Zonary nature of the canine placenta, once a fetus exceeds its due date by more than 2 day, it will demand more nutritional support than the placenta is able to provide, Resulting in intrauterine fetal death.

Hence it is critical to ensure that fetus has attained but not exceeded, Its maximal gestational age prior to delivery (Jayakumar, 2017).

There are several etiological factors responsible for Singleton puppy syndrome, which include breeding of older animals, Death of embryos during early gestation and resorption of embryos before mineralization.(M. H. Pitroda,2019). 


\section{Case history and observations}

A Two year old Labrador she dog in her first parity was presented to Veterinary Clinical Complex (VCC), Post Graduate Institute of Veterinary Education and Research (PGIVER), Jamdoli, Jaipur with the history of breeding approximately 68 days before and failure to deliver on the expected day of whelping.

Clinical examination revealed restlessness and presence of greenish discharge hanging out from vulva with limbs of pup or fetal membrane in the birth canal. During the course of examination engorged mammary glands were also observed. A lateral abdominal radiograph from right side was performed which confirmed the presence of single fully-grown fetus with posterior presentation in the uterus. After confirmation byradiograph and clinical examination the case was diagnosed as dystocia because of the single pup in the bitch.

\section{Treatment and Discussion}

The medical treatment for dystociadue to single puppy syndrome was attempted with Inj. Calcium Sandoz 10\% (Novartis; $10 \mathrm{ml}$ ) (Every $5 \mathrm{~min}$. Interval $2 \mathrm{ml}$ calcium Sandoz, slow IV),After 15 mint. Inj. Oxytocin $0.4 \mathrm{ml}$ (5 IU) Slow IV With Inj. Dextrose $250 \mathrm{ml}$ Intravenous. Wait for $2 \mathrm{hrs}$ during this period increase uterine contraction and amount of greenish discharge but fails to deliver pup. After two hours inj. calcium Sandoz 10\% (Novartis; $8 \mathrm{ml}$ ) (Every $5 \mathrm{~min}$. Interval $2 \mathrm{ml}$ calcium Sandoz, slow IV), after 10 min Inj. Oxytocin $0.8 \mathrm{ml}$ (5 IU) (divided two dose of $0.4 \mathrm{ml}$ interval, every $3 \mathrm{~min}$. interval) Slow IV With Inj. Dextrose $250 \mathrm{ml}$ Intravenous. After 10 min mature dead fetus was delivered.

Fig.1 Greenish vaginal discharge during the course of treatment.

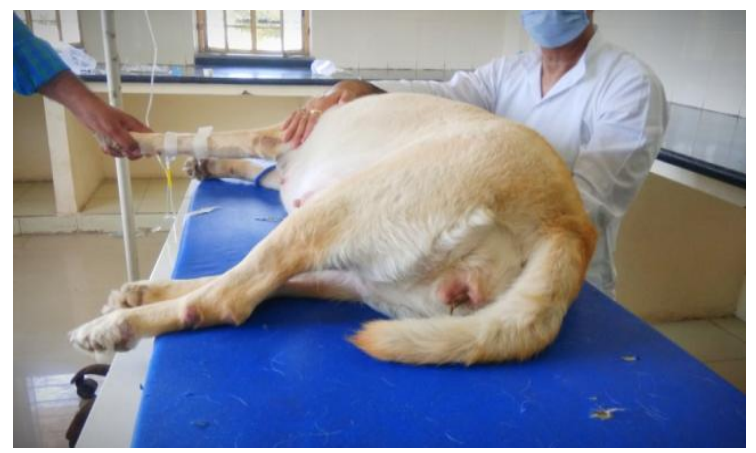

Fig.2 Radiograph of the bitch confirmed presence of one fullydeveloped fetus.

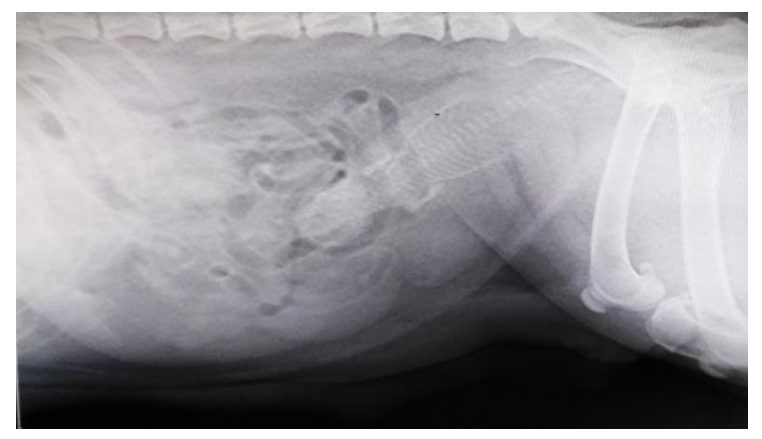


Fig.3, 4 Mature dead fetus delivered per Vaginally.

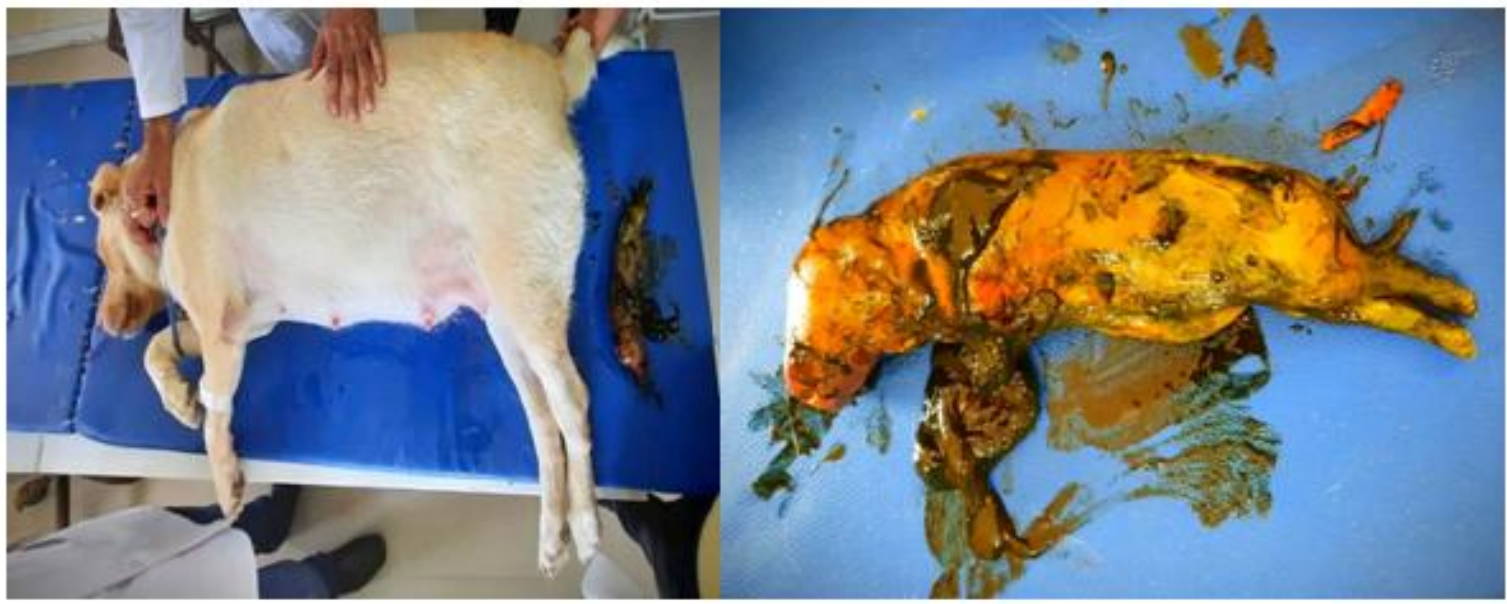

The dystociadue to single puppy syndrome can be diagnosed by radiography and ultrasonography and treated by fluid therapy along with oxytocin and calcium.

\section{Acknowledgment}

The authors is highly thankful for the Department of Veterinary Gynaecology and Obstetrics, PGIVER Jaipur Rajasthan India for providing necessary facilities for this work.

\section{References}

Davidson, A. P. (2011). Primary uterine inertia in four labrador bitches. Journal of the American Animal Hospital Association, 47(2), 83-88.

Domoslawska A, Jurczak A, Janowski T. A onefoetus pregnancy monitored by ultrasonography and progesterone blood levels in a German Shepherd bitch: a case report. Veterinarni Medicina. 2011; 56:5557.

Ganesan A, Sankar P, Ninu A R, Mohanambal K, Enbavelan P A, Ram Prabhu R. A rare case of single pup syndrome and its management in a Labrador bitch. Indian Journal Animal Research. 2016; 2:395-397.

Givens M D, Marley M S D. Infectious causes of embryonic and fetal mortality
Theriogenology. 2008;70:270-285

Jackson PGG. Dystocia in the dog In: Hand book of Veterinary Obstetrics (ed), Saunders and Imprint of Elsevier Ltd. Edinbourgh. 2004; 2:141-16

Jayakumar, C., Chinnu, P. V., Amritha, A., \& Unnikrishnan, M. P. Challenges In Management of Canine High Risk Pregnancies With Single Pup Syndromie. 2017, 22-26.

PeetalaV., Murthy, V. C., Murthy, N., Achuthrao, U. H., Ravindranath, B. M., \& Panchaxarayya, G. Clinical Efficacy of Mifepristone and Misoprostol in Induction of Parturition in Female Dogs with Single Pup Syndrome. International Journal of Livestock research vol. 9(8) Aug

Pitroda, M. H., Mali, A. B., Rangnekar, M. N., Amle, M. B., \& Tumbare, P. J. (2019). Dystocia due to single pup syndrome in a Rottweiler she dog: a case report. Haryana Veterinarian, 58 (Special Issue), 129-130.

Shekher, S. C., Prakash, Y. S., Lal, Y. C., \& Vimlesh, K. A rare case of single pup syndrome and its management in Labrador bitch: A case report. Journal of Entomology and Zoology Studies 2020; 8(4): 1723-1724

Sridevi, P. (2015). Canine reproduction. The theory and practice. 1st Edn. Active Ads \& Printers Pvt. Ltd., Hyderabad. 


\section{How to cite this article:}

Abhay Kumar Meena, Pravin Kumar Meena, Manish Kumar and Krishan Yadav. 2021. Handling of Dystocia due to Single Pup Syndrome in Labrador Bitch: A Case Report. Int.J.Curr.Microbiol.App.Sci. 10(08): 88-91. doi: https://doi.org/10.20546/ijcmas.2021.1008.011 